\title{
The Utilization of Computer in Teaching Chemistry and Its Impact On Education Achievement for Grade 11 Students
}

\author{
Azhari Abdul Rahim Ahmed Darwish ${ }^{1}$, Baraa Saeed Hamad*,1,2 \\ ${ }^{1}$ College of Education, Sudan University of Science and Technology, Sudan \\ ${ }^{2}$ Al-Maarif University College, Iraq \\ *baraa.saaed@gmail.com
}

KEYWORDS: $\quad$ Using Computer, Teaching, Chemistry, Impact, Academic Achievement.

\begin{abstract}
:
Today, the world is witnessing technological progress in various fields and has laid the foundations for a new global culture. Today, we live in a world in which Internet users have exceeded the barrier of five billion through mobile phones and social networking sites, and they all publish millions of information on various topics and are widely used as tools of knowledge. And scientific and social interaction, to complement another part of the technology systems used in teaching and learning and contribute to the delivery and employment of knowledge and work to remove the learner from the monotony and boredom imposed by traditional methods in the field of education and in the use of computers. This paper comes to investigate the impact of using computers in teaching chemistry at grade 11 students in the province of Anbar, Iraq.
\end{abstract}

\section{REFERENCES:}

(Ozmen, H. ,2008, The influence of computer-assisted instruction on students' conceptual understanding of chemical bonding and attitude toward chemistry: A Case for Turkey. Computers and Education, 51, 423-438.

Borstorf, P. \& Lowe, S. (2006). E-learning, Attitudes and Behaviors of end-users. Allied Academics International Conference. Academy of Educational Leadership Proceedings, 12(7): 45-53

Izzet Kara and Ozkan Kahraman, 2008. The Effect of Computer Assisted Instruction on the Achievement of Students on the Instruction of Physics Topic of 7th Grade Science Course at a Primary School. Journal of Applied Sciences, 8: 1067-1072.

Madden, A. Ford, N. Miller, D. and Levy, P.2005, "Using The Internet in the teaching, the views of practitioners (Asurvey of the views secandaray school teachers in Sheffield, UK. (Electronic version)". British Journal of Educational Technology: Mar 2005, 36(2), 25- 255.

Min, H.,2005, "Exploring high school student preferences toward the Constructivist Internet based Learning environs ments in Taiwan (Electronic Version)". Educational Studies, 31(2), 149- 255

Serin, Oguz. (2011): "The Effects of the Computer- based Instruction on the Achievement and Problem solving skills of the science and technology students", Turkish Online Journal of Educational Technology, 1(10).

Sowunmi, Olubola and Aladejana, Francisca (2013), Effect of Simulation Game and Computer Assisted Interaction on Performance in Primary, Science. West East Journal of Social Sciences,2(2)117-122.

Sugar, W., \& Crawley, F. \& Fine, B. (2005). Critiquing Theory of Planned Behavior as a method to assess teachers' technology integration attitudes. British Journal of Educational Technology, 36 (2): 112- 184.

Taban Habibu, Md. Abdullah-Al-Mamun, CheKum Clement,2012, Difficulties Faced by Teachers in Using ICT in Teaching-Learning at Technical and Higher Educational Institutions of Uganda, International Journal of Engineering Research \& Technology, Vol. 1 Issue 7, September.

Yuen, A. \& Ma, W. (2008). Exploring Teacher Acceptance of E-Learning Technology. Asia-Pacific Journal of Teacher Education, 36(3): 229. 
استخدام الحاسوب في تدريس مادة الكيمياء وأثرة على التحصيل الدراسي لطلاب الخامس العلمي

$$
\begin{aligned}
& \text { أ.د. ازهري عبد الرحيم احمد درويش 1، براء سعيد حد*1،1، } 2
\end{aligned}
$$

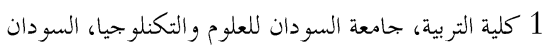

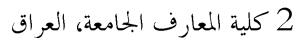

$$
\text { الكلمات المفتاحية | استخدام الحاسوب، تدريس، الكيمياء، تأثير، تحصيل دراسي. }
$$

Crossref doi https://doi.org/10.51345/.v32i2.393.g224

\section{ملخص البحث:}

يشهد العالم اليوم تقدماً تقنياً في شتى المجالات، وأرسى قواعد ثقافة عالمية جديدة، فقد أصبحنا اليوم نعيش في عالم تجاوز

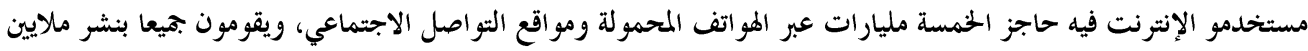

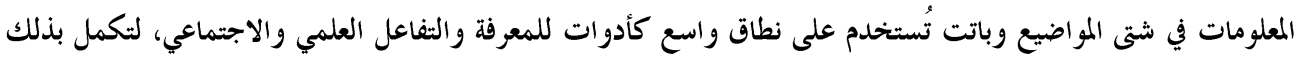

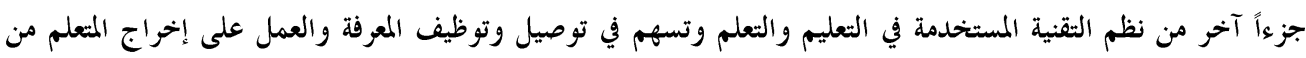

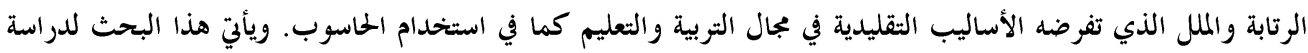
تأثير استخدام الحاسوب في العملية التعليمية لطلبة الصف الحامس الثانوي - الفرع العلية العلمي في في محافظة الأنبار - العراق.

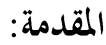

بدأ استخدام الحاسوب في عمليتي التعليم والتعلم في السنوات الأخيرة في الدول المتقدمة، وتعد تقنية

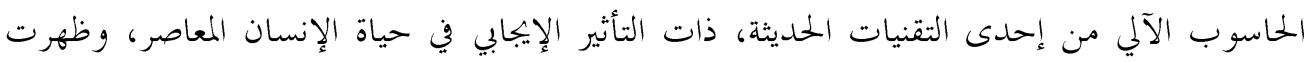

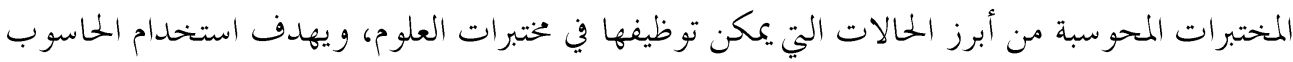
في إجراء التجارب العلمية إلى مساعدة المعلم والمتعلم على إجراء التجارب الكيميائية بوقت قصير،

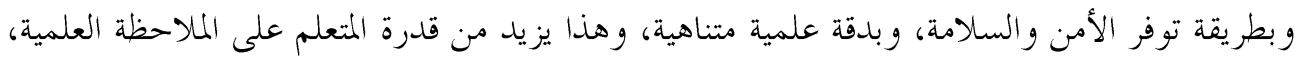

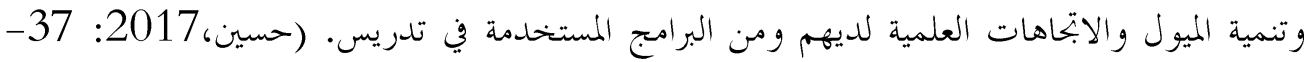

ويعد الحاسوب وسيلة تخرج الطلبة من روتين الحفظ والتلقين إلى العمل، وينمي فيهم ابحاهات إيجابية

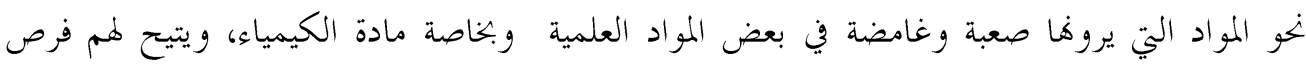
التعلم الذاتي، وينقل عملية التعليم والتعلم إلى المتزل لاستمرار اكتساب المهارات، ويساعد المعلم في تئي 
الكشف عن الفروق الفردية والتغلب عليها بوصفه مصدر اً للمعلومات في المواد التعليمية ومنها الكيمياء

وعلم الكيمياء كما هو معلوم يدرس الجزيئات والذرات والتفاعلات، اي التعامل هنا مع ذرات متصلة مع بعضها بطريقة ما لتكوين هذه الجزيئات ذلك يجتاج إلى خيال واسع كي يتسنى لنا معرفة كيفية ترابط هذه الجزيئات مع بعضها البعض لتكوين المركبات، وفي السابق كان هناك شفافيات و بخسمات ولوحات توضيحية و كلها محلو دة الإمكانيات، وعند توظيف الحاسوب فإننا نمتلك إمكانيات هائلة لو أحسنا توظيفها مع توافر الأدوات المناسبة لأمكن تدريس الكيمياء بطريقة مشوقة لتوصيل المعلومة ووضعها بطريقة أفضل وأسهل وأمكن كذلك توظيف إمكانيات الطلبة، كما أنه للتعليم الحاسوبي العديد من الخصائص التي تخلق منه بيئة تعليمية مشوقة للمتعلم فمن هذه الخصائص توفيره بيئة تعليمية تعلمية فيها خبرات تعليمية بعيدة عن المخاطر كإجراء التجارب الخطرة ومعامل الكيمياء ومواقع الانفجارات البركانية، يكتاج المتعلم في هذا النمط من التعليم إلى توافر تقنيات معينة مثل الحاسوب وملحقاته والانترنت والشبكات المحلية، لذا تأتي أهمية الحاسوب في العملية التعليمية، وأهمية تطوير أساليب التدريس واستخدام الحاسوب كوسيلة تعليمية في تدريس المواد عامة ومادة الكيمياء بصفة خاصة والتي تعتبر من المواد المهمة بالمرحلة الثانوية.(عامر،2016: 73).

\section{مشكلة البحث:}

نظراً لأهمية مشروع استخدام الحاسب الآلي في تدريس مادة الكيمياء للصف الخامس العلمي ولا للبرامج الخاسوبية من أهمية في عملية التعلم لدى الطلبة، ولا لاحظه الباحث أثناء زيارته للمدارس ورغم وجود الحاسوب في اغلب المدارس الا ان استخدامها في التدريس لم يكد يذكر، وتم إجراء دراسة استطلاعية من خحلال تطبيق استبانة مبدئية على بحموعة من مدرسي ومدرسات الكيمياء بسؤال هل توظيف الحاسوب في تدريسك للكيمياء وهل تعتقد انه سيزيد من تحصيل الطلبة في الكيمياء، كانت ابجاهاهم ايجابية لاستخدام الحاسوب عند تدريس الكيمياء وتوقعوا ان استخدامه سيزيد من تحصيل طلبتهم وذكروا معوقات لاستخدامه في التدريس,ورعليه يمكن صياغة مشكلة البحث في السؤال المحوري التالي: ما اثر استخدام الحاسوب في تدريس مادة الكيمياء واثره على التحصيل الدراسي لطلاب الخامس علمي بالمرحلة الثانوية محافظة الانبار -العراق. 


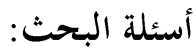

وسعياً للتعرف على هذه المشكلة قام الباحث بصياغة الأسئلة الآتية:

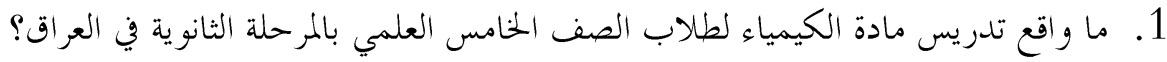

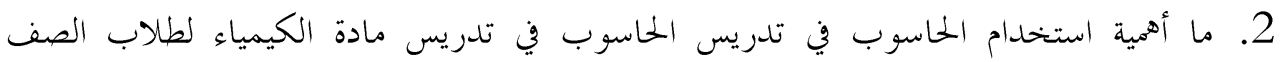
الخامس العلمي بالمرحلة الثانوية؟

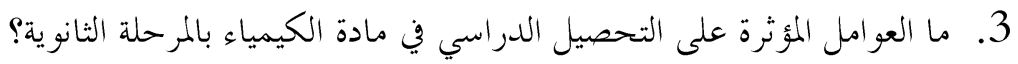

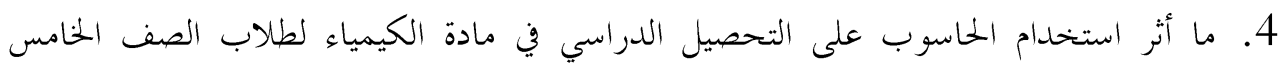
العلمي بالمرحلة الثانوية في المستو يات المعرفية؟ الماتع 5. ما أهم معوقات استخدام الحاسوب في تدريس مادة الكيمياء لطلاب الصف الخامس العلمي بالمرحلة الثانوية؟

\section{أهداف البحث:}

يسعى هذا البحث لتحقيق الأهداف الآتية:

1. التعرف على واقع تدريس مادة الكيمياء لطلاب الصف الخامس بالمرحلة الثانوية. 2. التعرف على أهمية استخدام الحاسوب في تدريس الكيمياء لطلاب الصف الخامس بالمرحلة الثانوية.

3. معرفة العوامل المؤثرة على التحصيل الدراسي في مادة الكيمياء لطلاب الصف الخامس علمي الثنانوي.

4. معرفة أثر استخدام الحاسوب على التحصيل الدراسي في مادة الكيمياء لطلاب الصف الخامس علمي بالمرحلة الثانوية. 5. معرفة معوقات استخدام الحاسوب في تدريس مادة الكيمياء لطلاب الصف الخامس العلمي بالمر حلة الثنانوية. 6. تقليم توصيات ومقترحات استناداً على نتائج البحث تساعد على رفع التحصيل الدراسي للطلاب ومعالجة المشاكل المتعلقة بالموضوع. 


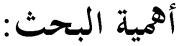

1. تتمثل أهمية البحث في اهمية الموضوع حيث أن استخدام الحاسوب في تدريس المواد العلمية يساعد في تحسين مستوى التحصيل الدراسي لطلاب المرحلة الثانوية. 2. قد تساعد نتائج البحث معلمي الكيمياء في تطوير طرائق تدريس الكيمياء وذلك باستخدام الوسائل التلعيمية الحديثة في التدريس. 3. قد يسفر هذه البحث عن نتائج تمثل إضافة جديدة للمكتبة العربية في بحال المناهج وطرائق

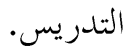

4. قد تسهم نتائج البحث في مساعدة غخططي المناهج بالمرحلة الثانوية في تطوير المناهج الدراسية بصورة عامة ومناهج الكيمياء بصفة خاصة. 5. نتائج البحث تسهم في مساعدة الجهات المختصة باستبدال البيئة التعليمية للمدارس بالمرحلة الثانوية إلى البيئة الالكترونية الحديثة.

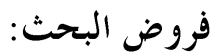

يجري البحث تحت الفروض الآتية: 1. يستخدم مدرسو مادة الكيمياء طرائق التدريس التقليدية في تدريس طلاب الصف الخامس العلمي بالمرحلة الثنانوية.

2. للحاسوب أثر مهم في تدريس مادة الكيمياء لطلاب الصف الخامس العلمي بالمرحلة الثانوية.

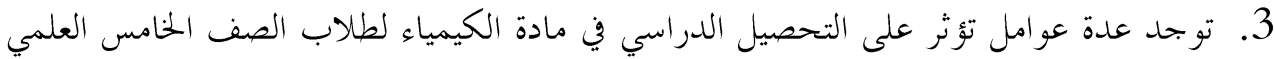
بالمر حلة الثانوية. 4. استخدام الخاسوب في التدريس يسهم في رفع التحصيل الدراسي لطلاب الصف الخامس العلمي في مادة الكيمياء بالمر حلة الثنانوية. 5. توجد معوقات في استخدام الحاسوب في تدريس مادة الكيمياء لطلاب الصف الخامس العلمي بالمر حلة الثانوية.

\section{حدود البحث:}

أولاً: الحدود الموضوعية: دراسة استخدام الحاسوب في تدريس مادة الكيمياء وأثره على التحصيل الدراسي (دراسة ميدانية على طلاب الصف الخامس علمي) المرحلة الثانوية. 
ثانياً: الحدود الزمانية: 2018م/2019م. ثالثاً: الحدود المكانية: العراق - محافظة الأنبار.

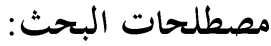

اولاً: الحاسوب: عرف بانه: ماكنة المتفاعلة مع الأوامر الإنسانية ذات التقنية المتطورة في معالجة البيانات

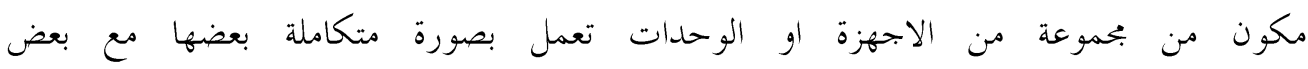

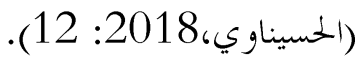
التعريف الاجرائي: جهاز الكترولي يقوم باستقبال البيانات المدخلة ومعالجتها وتخزينها وأخراجها في شكل معلومات جاهزة للاستخدام، حسب الطلب. ثانياً: الحاسوب في التعليم عرف بانه: بيئة تعليمية تساعد على تامين التفاعل بين الطالب والحاسوب

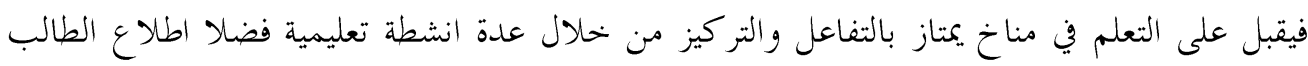
على استجاباته بصورة فورية (ريحان، 2019: التعريف الاجرائي: اراء توظيف الحاسوب في تدريس مادة الكيمياء وأثره على التحصيل الدراسي لطلاب الصف الخامس العلمي من وجهة نظر المدرسين.

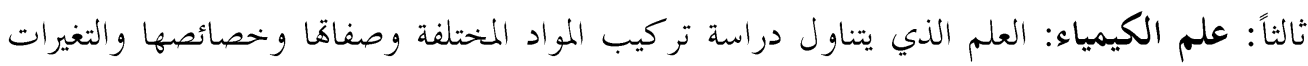

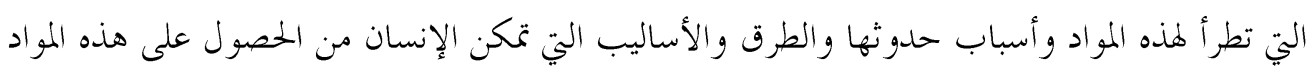

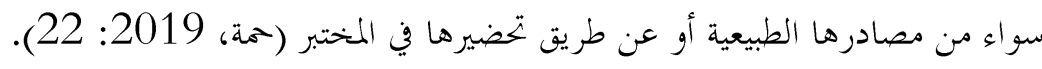
التعريف الاجرائي: العلم الذي يتعامل مع كيفية تكوين المواد وعناصرها يدرس لطلبة الخامس العلمي (التطبيقي والاحيائي)، مكون من سبع فصول (تطور مفهوم الذرة، قوى الترابط والاشكال الهندسية

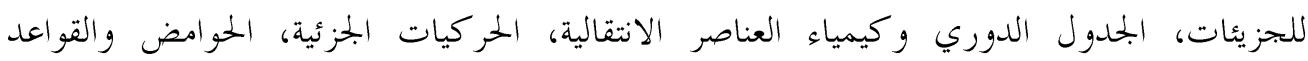

$$
\text { و الاملاح، كيمياء البوليمرات، الهيدرو كربونات الاروماتية). }
$$

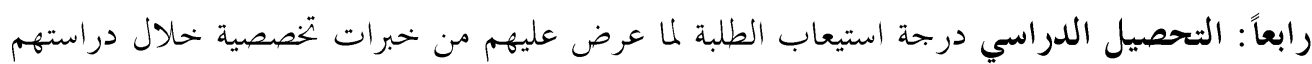
لمادة معينة في مدة زمنية محددة ويقاس بالدرجة التي يجصل عليها الطلبة في الاختبارات التحصيلية المعدة

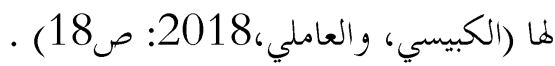
التعريف التحصيل الدراسي اجرائياً: مستوى النجاح في اكتساب المعارف والمهارات الذي ئيحرزوه طلبة الخامس علمي عند دراستهم مادة الكيمياء. 
الإطار النظري والدراسات السابقة

مفهوم تكنولوجيا التعليم

التكنولوجيا :عرفت بأها: علم تطبيق المعرفة في الأغراض العملية بطريقة منظمة وتعني فن التدريس

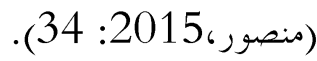

تكنولوجيا التعليم:

ارتبط مفهوم تكنولوجيا التعليم هو الاستخدام الأمثل للطرق والأساليب التطبيقية العملية والنظرية

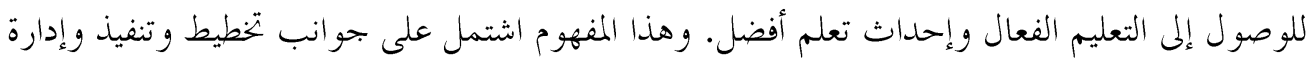
الموقف التعليمي، بطريقة تحقق الهدف التربوي من الخبرات التي يراد أن يمر بها المتعلم ويكتسبها (سلمان، .(12:2015

\section{تطور مفهوم تكنولوجيا التعليم:}

ارتبط مفهوم تكنولوجيا التعليم في بدايته بحاسة البصر، ومع تطور العلوم و المعارف، بدأت أهمية الحواس الأخرى بالظهور وخحاصة حاسة السمع، فظهرت الأجهزة التعليمية التي تستخدم حاستي السمع لئع

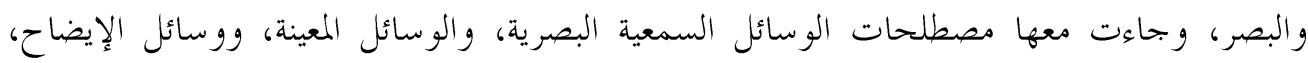
والوسائل التعليمية، و كان ذلك في أو وائل الستينيات من القرن الماضي. مر احل تطور تكنولوجيا التعليم: 1 - 1 - مرحلة التعليم البصري: تؤ كد الدراسات التي تناولت تاريخ تطور الوسائل التعليمية الى ان تكنولوجيا التعليم وتكنولوجبا التربية معرفة مبتكرة لثقافة بدأت ولدها إبان الثورة الصناعية الثانية في عصر الآلية وعصر القوة الذرية، حيث ترتبط تكنولو جيا التعليم هذا التطور ويمكن الاعتقاد بأذا بدأت في او ائل العشرينات. و يبين المخطط رقمث (1) تطور هذه المراحل.

المخطط رقم (1) توضيح لمراحل تكنولو جيا التعليم

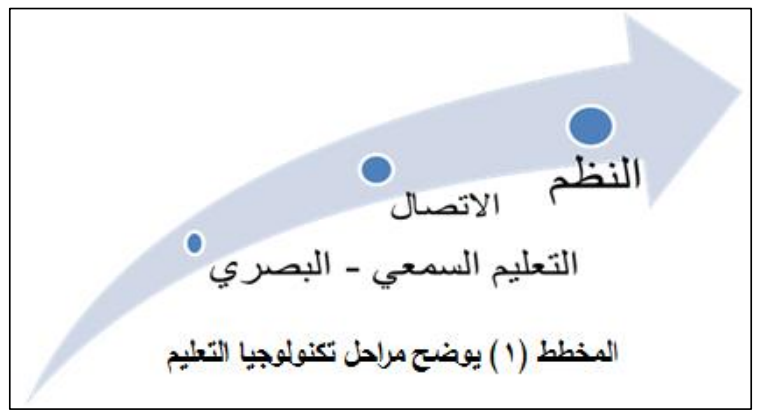




\section{وظائف تكنولوجيا التعليم (الفريحات، 2014: 30) :}

1. ان التطبيق الواعي للتكنولوجيا سوف يزيد من انتاجية العملية التعليمية وذلك بتحرير المعلم من الأعمال الروتينية.

2. المساهمة في التأكيد على أهمية الخبرة الحسية المباشرة كما يضع المتعلمين في مواقف تحفزهم على المى التفكير واستخدام الحواس.

3. بتعل التربية ذات طابع فردي إلى حد كبير، فتعني بالجميع ولكنها وفي نفس الوقت تتيح فرصة التعلم الذاتي للمتعلمين.

4. تحقق مقداراً من تكافؤ الفرص بإيصالها خبرات الثقافة والعلم إلى كل الأصقاع والمناطق النائبة و بذلك تتغلب على التباعد الجغرافي. 5. تستطيع تكنولوجيا التعليم إرساء قيام العمليات التعليمية أسس علمية إذا اعتمدت على نتائج البحوث الموثقة في التعليم البشري واستفادت من نتائجه. 6. تطوير المناهج الدراسية بحيث تصبح قادرة على استيعاب التطور التكنولوجي الحديث وإدخال المفاهيم الجلديدة في التعلم. 7. استحداث طرق تقويم جديدة تنسجم مع استراتيجيات التعلم لإتقان تلك الاستراتيجيات التي لا تقوم على أساس المفاضلة بين الطلاب بل على تسابق الفرد مع ذاته لتحقيق أهداف التعلم.

\section{دور الوسائل التعليمية وتكنولوجيا التعليم في تطوير التعليم:}

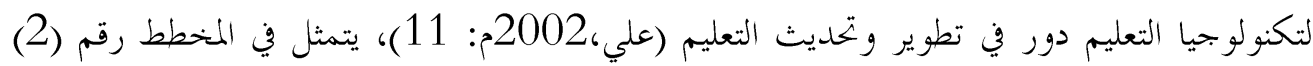
الآين:

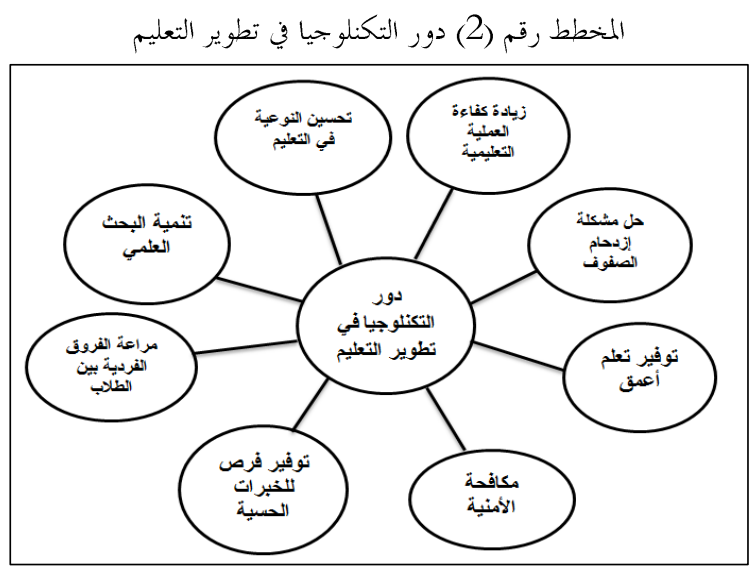




\section{تطبيق تكنولو جيا التعليم في التربية المدرسية:}

هناك بعض التوجهات التي من شأها أن تزيد من فعالية تكنولوجيا التعليم في التربية المدرسية وتتمثل في الآتي (على، 2002م: 29 ) : 29

1. أن يسعى المعلم لإكساب ذاته فهماً أشمل وأعمق في ماهية تكنولوجيا التعليم وإدراك دورها وأهميتها في تطوير التعليم.

2. أن يدرك المتعلم دوره الجمديد المتوقع له في ظل تبني تكنولو جيا التعليم في العملية التدريسية. 3. إنشاء وتدعيم مراكز مصادر التعلم والمكتبات الشاملة في المدارس. 4. تقويم وتطوير البيئات التعليمية بمظهريها النفسي والمادي المناسبين لتبين التعلم التكنولوجي تهي الحمديث.

5. تزويد بيئة التعلم من حيث الأجهزة والأدوات و المقاعد والستائر والتوصيلات الكهربية وغيرها ما يتعلق بقاعات التدريس. 6. تدريب المعلمين على بجالات استخدام تكنولو جيا التعليم. 7. تدريب الطلبة على كيفية التعامل مع التقنيات التعليمية الحمديثة. 8. توفير الحوافز المادية والمعنوية للمعلمين الذين يتبنون النموذج التكنولوجي المبهي المعاصر في التدريس. 9. تطوير المناهج الدراسية المواكبة للمستحدثات التكنولوجية.

\section{معوقات تطبيق تكنولوجيا التعليم في التربية المدرسية:}

تعددت الأسباب التي تعزى إليها مقاومة المدرسين لتطبيق تكنولو جيا التعليم في التربية المدرسية، ومنها ما

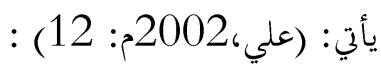
1. ميول بعض المعلمين إلى مقاومة التجديدات التربوية عامة، والاستراتيجيات والتقنيات الجديلدة المغايرة خاصة لما أعتيد عليه. 2. قلة الوعي .كمفوم تكنولوجيا التعليم، والنظر إليها على أها بجموعة الأجهزة والآلات المستخدمة في التعليم، والتي من شأها أن تفقده ذلك الطابع الإنساني، وبتعله آلياً ميكانيكياً .

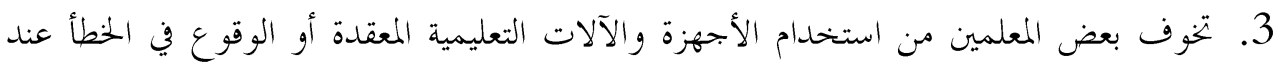

استخدامها.

4. قلة توفر الوقت الكافي للمعلم وانشغاله بالأعباء الروتينية للتدريس. 5. - 5لة الحوافز المادية والمعنوية. 
6. النظر إلى تكنولوجيا التعليم كعامل مهلد، وتخوف بعض المعلمين من أن تحل تكنولوجيا التعليم

محلهم.

7. صعوبة الخصول على البربحيات والأجهزة والآلات التعليمية اللازمة للموقف التعليمي التعلمي.

8. عدم إيمان بعض المعلمين بالقيمة التربوية لتكنولوجيا التعليم في العملية التعليمية .

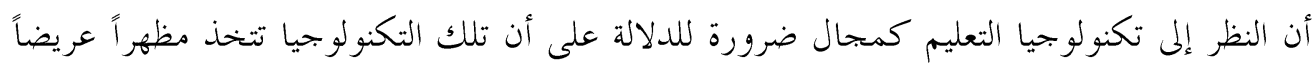

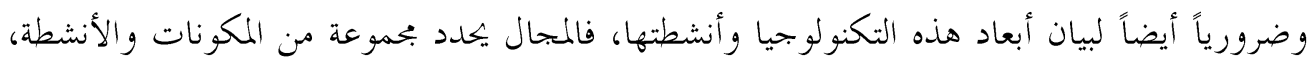

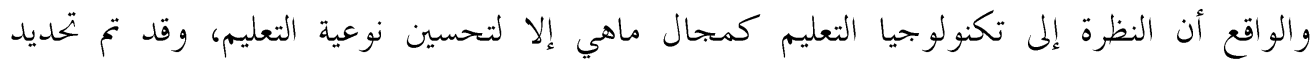

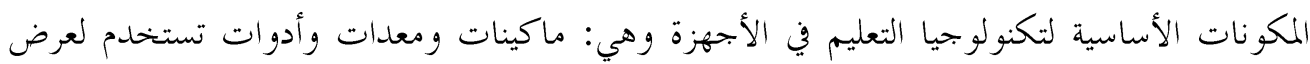
و نقل المحتوى التعليمي مثل (الكمبيوتر - الفيديو -التلفزيون- جهاز تعلم اللغات).

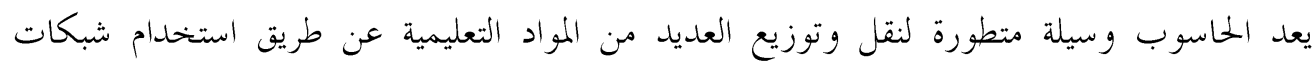
الاتصال الحديثة. إلى جانب ذلك، يملك الحاسوب الكثير من المزايا والخصائص والتي بتعل منه أداة تعليمية فريدة ذات فاعلية كبيرة منها ما يلي (الكبيسي، وفرحان، 2013: 57-58) :

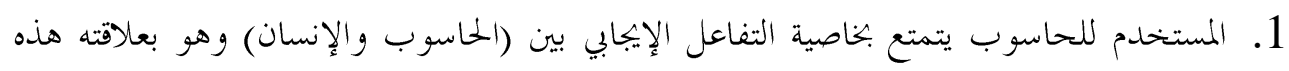
يختلف عن علاقته بالإذاعة المرئية التي يكون موقفه فيها موقفاً سلبياً.

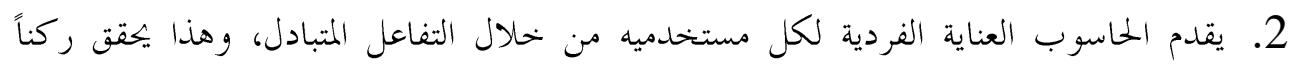
أساسياً من أركان التربية لا يستطيع الكثير من المعلمين تطبيقه في مفهومهم مع تزايد عدد

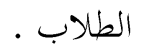

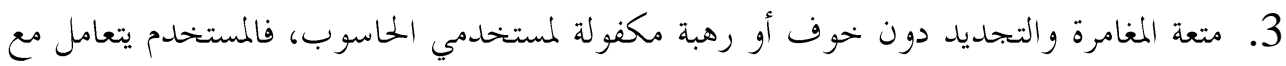

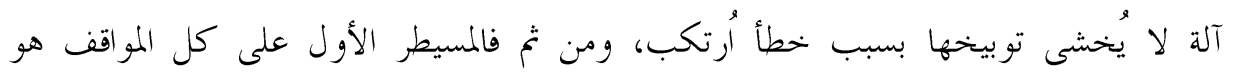
المستخدم، ويساعد نفسه بنفسه.

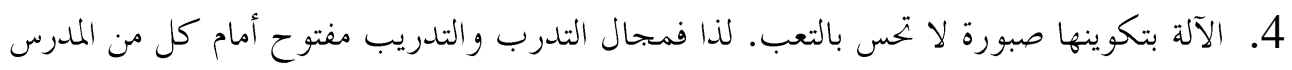
و الطالب، ومن تم يخف الضغط النفسي المصاحب لمواجهة المشكلات بالنسبة للطالب، وتتاح للمدرس فرصة أكبر لبذل المزيد من العناية الفردية لمن يحتاجها من طلابه. 5. التعلم من خلال المشاهدة والاستكشاف من الأمور التي تدعمها فلسفة التعليم في عصرنا

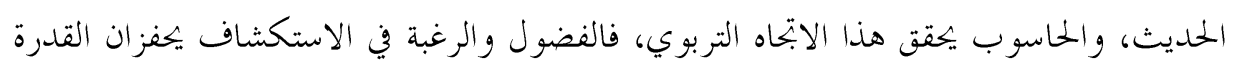
على التعلم المتجددد. 
6. يلعب الحاسوب دوراً مهماً في مراعاة الفروق الفردية من حيث القدرات الاستيعابية للدارسين، فكل طالب يسير في دراسته مع الحاسوب بالسرعة التي تناسب إمكاناته الذهنية والتحصيلية، فزمام القيادة في عملية التعليم يستلمها الطالب، مما يساعد على دعم الثقة بالنفس وفتح المجال أمام التحصيل والنمو.

\section{علم الكيمياء تطوره و اهميته :}

يعتبر علم الكيمياء من أهم العلوم التي ساهمت ومازالت تسهم في تطور وتقدم البشرية، وذلك بما تؤديه

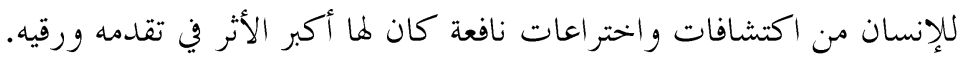
أصلها عربي من الفعل كمي، أي اخفي، كمي، يكمي شهادته وغيرها و كتمها، وظهرت في حوالي

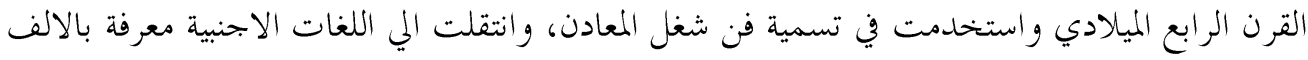

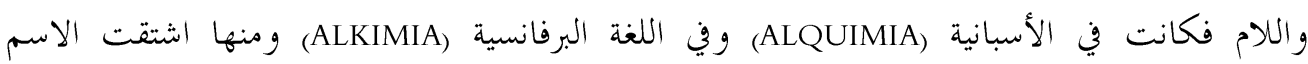
الانجليزي (ALKHEMY) وهنالك من يقــول ان أصسلها إغريقي وهي سيمياء أو خيمياء وتعني

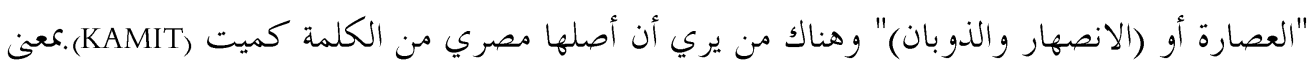

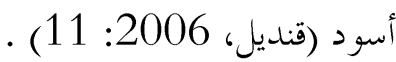

\section{أهمية علم الكيمياء:}

قد لعب علم الكيمياء في الماضي ولا يزال يلعب دورًا أساسيًا وحيويًا في تطوير حياة الإنسان، ويسهم

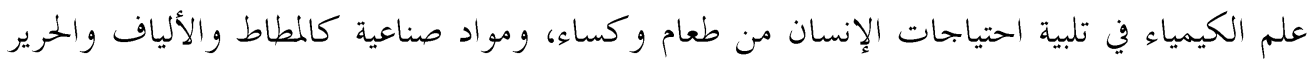

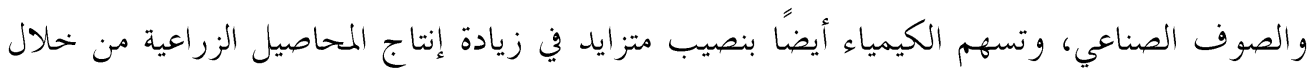
إنتاج الأسمدة والمبيدات, وتسهم الكيمياء في الصناعات الصيدلانية.، ويمكن أن يكون لعلم الكيمياء

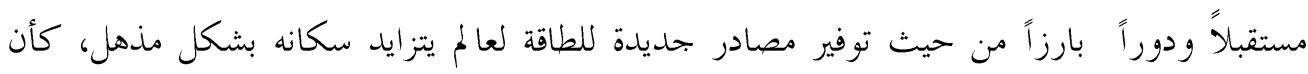

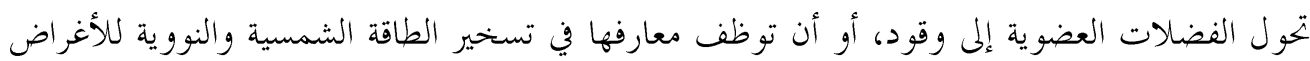
السلمية (عامر، 2004: 4: 4)

وبسبب دور الكيمياء المشار إليه في الأمثلة السابقة في حياة المجتمع وغيرها، فقد وصفت الكيه الكيمياء بأها

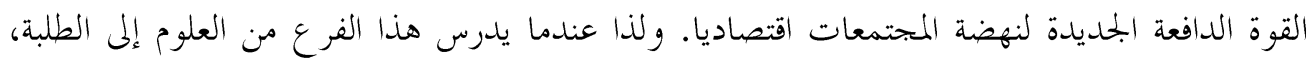
تكون الغاية أن يدرك الطلبة كيف أن هذه المعارف ذات أثر في رخاء ورفاهية البشر كما هو لباقي

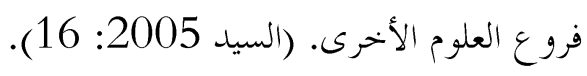




\section{الوسائل التعليمية في تدريس الكيمياء: - الو إن}

يقصد بالوسائل التعليمية بأها بحموعة الأجهزة والأدوات والمو اد التعليمية التي يستخدمها المعلم لتحسين

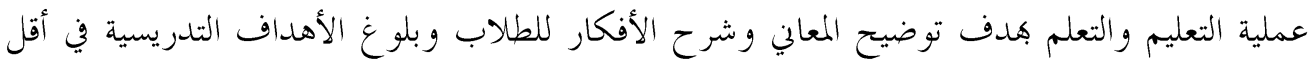
وقت وجها مُكنين دون الإستناد إلى التعليم اللفظي. ويؤكد الأدب العلمي على أهمية استخدام الوسائل التعليمية المختلفة في التدريس الفعال للكيمياء من

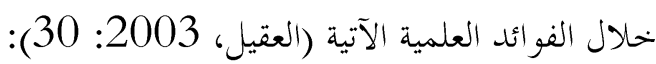

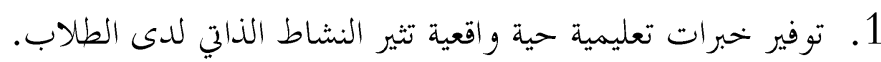

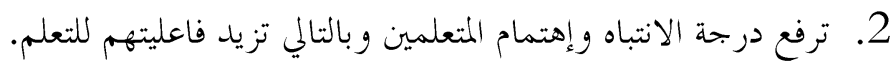
3. تساعد المتعلم على صياغة أفكار جديدة وربطها بخغبراته السابقة. 4. تنمي الميول والابحاهات العلمية لدى الطلاب والتي قد تقود للإبداع. 5. تساعد في تذكر المادة التعليمية والاحتفاظ بها وتقلل من عامل النسيان. 6. تسهم في توضيح المعاني ومن ثم تزيد الحصيلة اللغوية للطلاب.

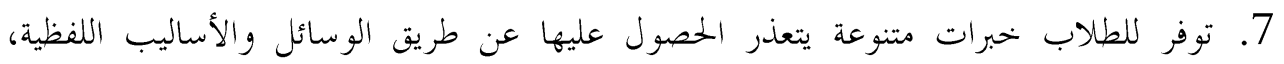
و وتسهم في تحقيق التعلم وفاعليته.

\section{الدارسات السابقة}

$$
\text { اولاً: الدراسات العربية }
$$

\section{1- دراسة ( أشرف الصايغ، و سحر فضل عبد الحميد عليان، 2019 )}

هدفت الدراسة الم معرفة أثر استخدام التعليم المحوسب في رفع التحصيل العلمي في مادة اللغة العربية لدى طالبات الصف الرابع الأساسي تكونت العينة من (37) طالبة مثلت المجموعة التجريبية والتي تم تدريسها باستخدام الدروس المحوسبة واستخدم الباحثان التصميم شبه التجريي للمجموعة الواحدة ذات الاختبار القبلي والبعدي، وقام الباحثان بإعداد اختبار بعدي على غرار الاختبار القبلي الذي تضمن

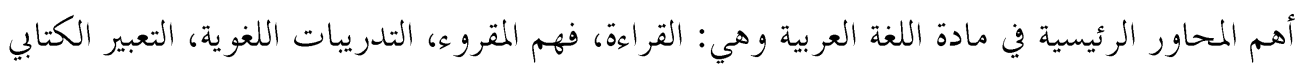
و الشفوي، الاملاء، لاختبار فرضيات البحث، وباستخدام الاختبار الثاني للعينات المرتبطة أظهرت النتائج وجود فروق ذات دلالة احصائية بين الاختبار القبلي والبعدي لصالح الاختبار البعدي في رفع التحصيل العلمي لمادة اللغة العربية، وقد تم التحليل لجميع المجالات (القراءة، فهم المقروء، التدريبات، التعبير، لئل 
الاملاء) ولوحظ وجود فروق ذات دلالة احصائية بين الاختبار القبلي والبعدي لصالح الاختبار البعدي لكافة المجالات بلدرجات متفاوتة أعلاها القراءة وأقلها التدريبات اللغوية يعزي ذلك إلى طريقة التدريس بالحاسوب.

\section{2- دراسة (رواء ابراهيم عيسى، و عاطفة جليل صالح، 2019) في العراق}

هدف الدراسة إلى التعرف على صعوبات استخدام عينة من اعضاء هيئة التدريس في كلية التربية الأساسية في الجامعة المستنصرية لتكنولوجيا التعليم الحلديثة في تدريسهم، ومدى ارتباط درجة استخدامهم الفعلي بالمتغيرات (المؤهل العلمي، و المؤهل الأكاديمي، والتخصص، وسنوات الخبرة)، استخدم المنهج الوصفي، وتمثلت أداة للبحث عبارة عن (استبانة) لمعرفة وجهات نظر اعضاء العينة وتم ثبات وصدق الاستبانة، وتحتوي الاستبانة على الصعوبات التي تحول دون الاستخدام الفعال للتكنولوجيا من وجهة العينة وهل توجد علاقة بالمتغيرات، وقد استخدمت النسب المئوية والتكرارات والوسط المرجح لتحليل البيانات وبإستخدام البرنامج الإحصائي (SPSS) أظهرت نتائج البحث عن وجود بعض العو ائق التي تعيق استخدام اعضاء هيئة التدريس لتكنولوجيا التعليم في التدريس؛ كان من أهمها عدم تو افر التجهيزات والبنى التحتية اللازمة، وبعضها مرتبط بضعف الدورات التدريبية في كيفية توظيف تكنولوجيا التعليم الحلديثة في التدريس.

\section{3- دراسة (نواري بوبكر، 2017) في الجزائر}

رسالة ماجستير غير منشورة، كلية العلوم الاجتماعية والإنسانية، جامعة، الطاهر مولاي سعيدة. هدفت الدراسة الى التعرف على ابتحاهات المعلمين نخو استخدام الحاسوب في التعليم الابتدائي، ومعرفة أثر الجنس والخبرة على ابتحاهاته، وكانت الإشكالية ما طبيعة الابتحاهات المعلمين نخو استخدام الحاسوب في التعليم الابتدائي، وقد استخدمت الاستبانة كأداة للدراسة حيث تكونت من (24) فقرة وذلك بعد ان صممت وتم التأكد من صدقها ومدى مناسبتها في تطبيقها على الدراسة الأساسية ثم وزعت على عينة تكونت من (80) معلم ودعلمة من المدارس الابتدائية واظهرت النتائج وجود ابحاهات إيجابية لدى المعلمين نحو استخدام الحاسوب في التعليم الابتدائي، حيث بلغ المتوسط (3.51) الحسابي الكلي لتقدير المعلمين على مقياس الابحاهات في استخدام الحاسوب في التعليم الابتدائي. وعدم وجود فروق ذات دالة إحصائيا تعزى لمتغيرات (الجنس والخبرة ) عند مستوى الدلالة (0.05). 


\section{4- دراسة (أديب حمادنـــــة، جميلة السرحان، 2015) في الاردن}

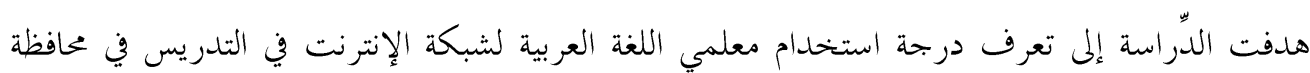

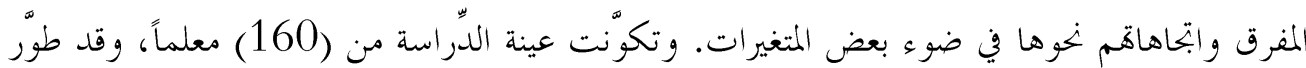

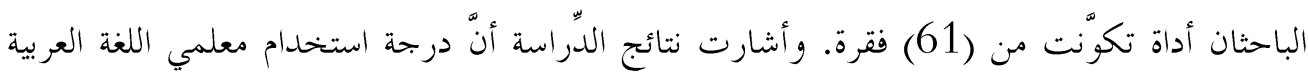

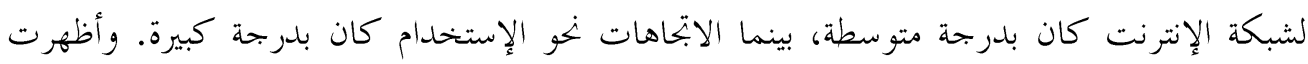
أيضاً وجود فروق في درجة استخدام شبكة الإنترنت تعزى لأثر متغيري المؤهل العلمي لصالح حملة

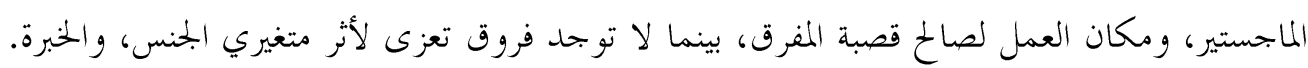

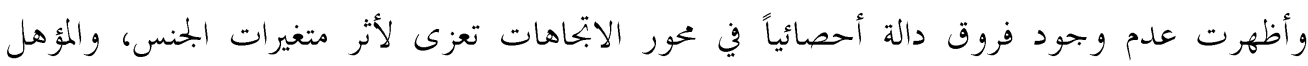
العلمي، والخبرة في التدريس، ومكان العمل. وأوصت الدرّاسة اعتبار استخدام شبكة الإنترنت في تعليم

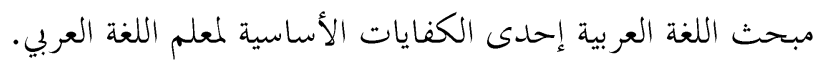

\section{ثانياً: الدراسات الاجنبية}

\section{1 - دراسة (Sowunmi \& Aladejana.2013) في نيجيريا}

هدفت الدراسة الم بيان اثر التدريس بمساعدة الحاسوب على التحصيل الطلاب في العلوم في المدارس المرحلة الابتدائية وقد استخدم المنهج شبه التجريي ولتحقيق الدراسة اعد اختبار تحصيليا، وتكونت العينة من (150) طالباً ثم تقسمهم الى ثلاث مجموعات: بحموعتين تجريبيتين وبحموعة ضابطة، المجموعة

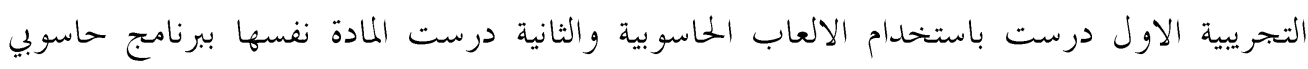

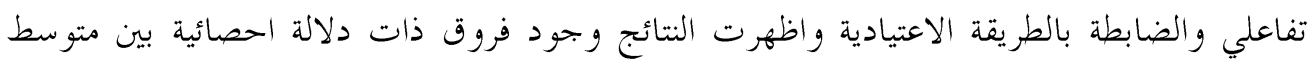
درجات طلبة المجموعتين التجريبيتين والضابطة لصالح المجموعتين التجريبيتين تعزى لاستخحام الطريقة الحاسو بية و لم تظهر فروق ذات دلالة احصائية بين المجموعتين التجريبيتين.

2- دراسة (Taban Habibu, Md. Abdullah-Al-Mamun, CheKum Clement,2012) في أوغندا هدفت الدراسة إلى اكتشاف الصعوبات التي يواجهها المعلمون في استخدام تكنولوجيا المعلومات والاتصالات (ICT) في التدريس والتعلم في الفصول الدراسية في مؤسسات التعليم التقني والتعليم العالي

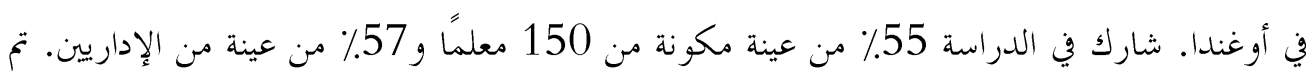
استخدام اختبار مربع كاي والمتوسط المرجح باستخدام برنامج الحزمة الإحصائية للعلوم الاجتماعية (SPSS) تكنولوجيا المعلومات والاتصالات في عملية التعليم والتعلم على الرغم من الصعوبات. كانت المعوقات 
الرئيسية هي الافتقار إلى برامج أصلية، وعدم كفاية أجهزة الكمبيوتر في الفصول الدراسية، والإنترنت منخفض السرعة، ونقص الحافز من جانب كل من المعلم والطالب لاستخدام تكنولوجيا المعلومات

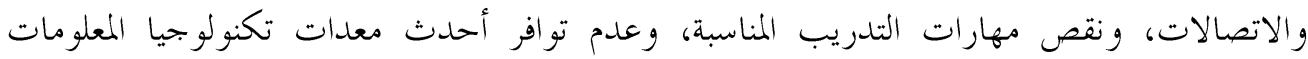
والاتصالات، و نقص الموظفين الفنيين الخبراء، ضعف الدعم الإداري، وضعف المناهج الدراسية وما إلى ولى ذلك. تم اقتراح التطوير المهني المستمر للمعلمين لوضع نموذج لأدوات التدريس وأدوات التعلم الجديدة ولعيد همدف تعزيز عملية التعلم والتعليم. من المهم لمدربي المدرسين وصانعي السياسات فهم الحواجز والفعالية

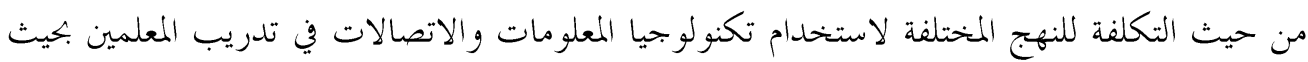
يمكن استكشاف استر اتيجيات التدريب بشكل مناسب لجعل هذه التغييرات قابلة للتطبيق على الجميع.

\section{3-3 دراسة (Serin,Oguz,2011) في تركيا}

هدفت الدراسة الى تقصي أثر استخدام الحاسوب في التدريس على تحصيل ومهارات حل المشكلة لطلبة

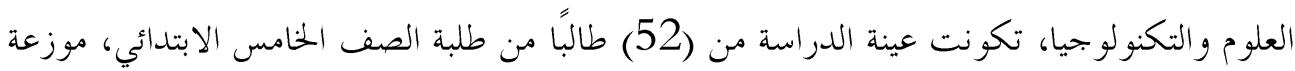

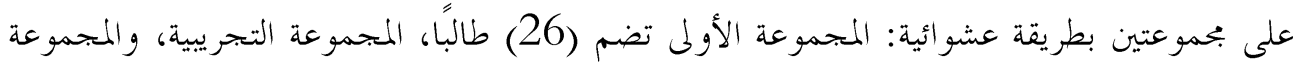

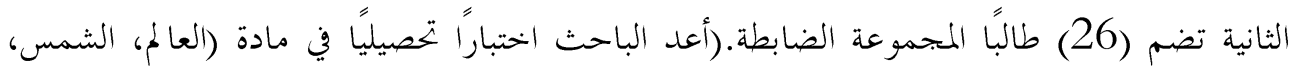

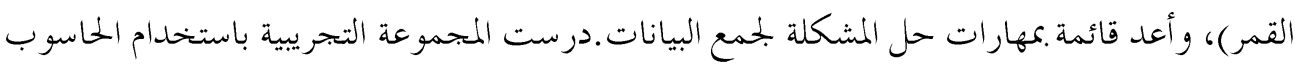

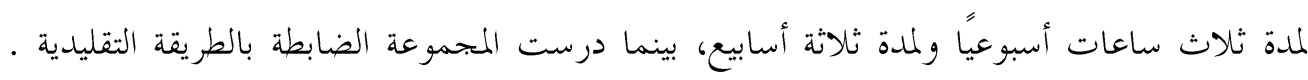

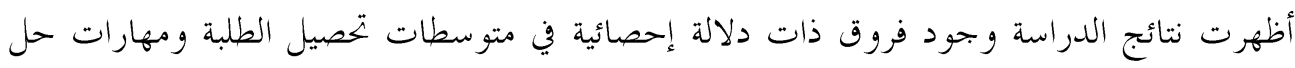
المشكلة بين المجموعتين ولصالح المجموعة التجريبية. 4- دراسة (Ozmen, H., 2008) في تر كيا

هدفت الدراسة الى استقصاء اثر تدريس المدعم بالحاسوب في فهم الطلاب للرو ابط الكيميائية و ابتحاههم

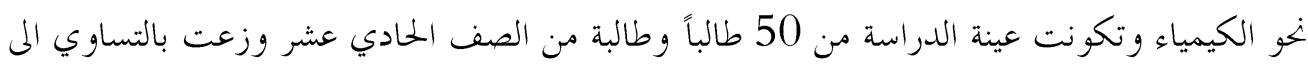
بحموعتين احدهما بحريبية درست باستخدام الحاسوب والاخرى ضابطة درست بالطريقة التقليدية وتمثلت الاداة بإعداد اختبار لقياس التحصيل واخر مقياس لقياس الاتجاه نغو الاحياء وكانت من نتائج الدراسة وجود فروق دالة احصائيا في متوسط تحصيل الطلبة في الكيمياء ومتوسط الابتاه بين المجموعة لإسياء التجريبية والمجموعة الضابطة ولصالح المجموعة التجريبية. 


\section{منهج البحث وإجر اءاته}

يتناول هذا الفصل إجراءات البحث و التي تتضمن شرحاً لمنهج البحث وعينته وتحليل البيانات الشخصية

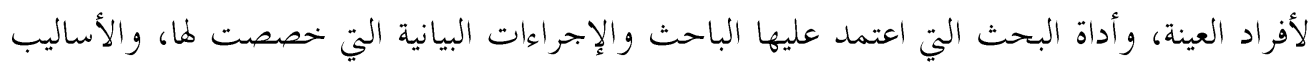
و المقاييس الإحصائية المستخحدمة في تحليل بيانات الاستبانة للوصول إلى النتائج.

\section{خطو ات البحث الميدانية:}

سعياً للإجابة عن أسئلة البحث و إثبات الفرضيات، أتبع الباحث الخطوات الآتية:

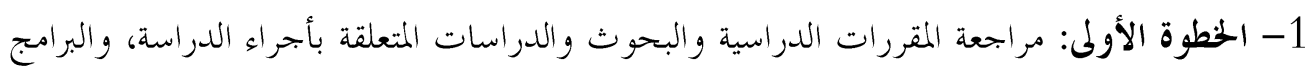
الحاسو بية المستخدمة في التدريس بالمرحلة الثانوية وكذلك عمل الباحث علي مراجعة الدراسات السابقة

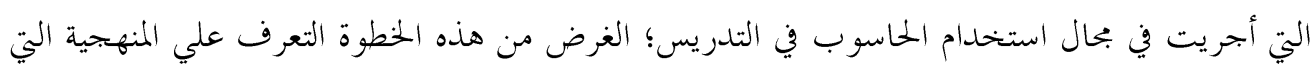
يتم ها تحديد الدراسة وتصنيفها وتحليلها, والنتائج التي توصلت اليها.

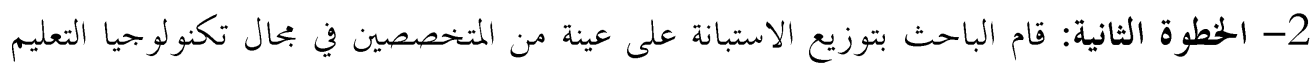
وطرائق التدريس بالمدارس الثانوية للتعرف على مدى وضوح عبارات الاستبانة وملامتها لأهداف

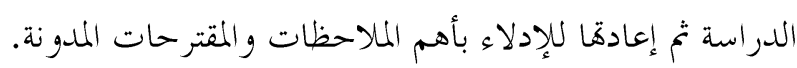

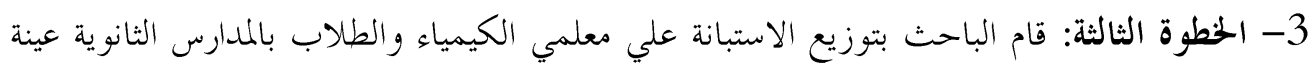
البحث .محافظة الأنبار في العراق وتم استلامها منهم.

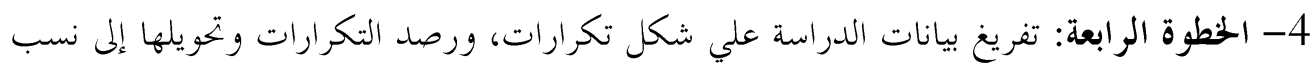
مئوية بغرض الوصول إلى نتائج البحث و تفسيرها ومناقشتها.

\section{منهج البحث:}

قام الباحث باستخدام المنهج الوصفي النحليلي الذي يقوم على جمع البيانات وتحليل نتائج تطبيق أداة البحث، وذلك لملائمته طبيعة هذا البحث وأهدافه.

\section{مجتمع البحث:}

يتكون بحتمع البحث من اعضاء هيئة التدريس (اختصاص مادة الكيمياء) والبالغ عددهم (776) (776)، منهم

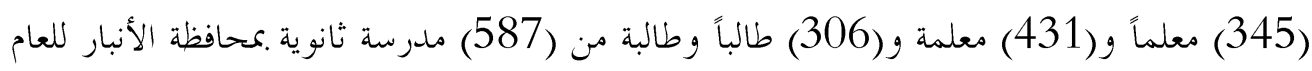
الدراسي منها (281) ثانوية بنين و(216) مدرسة بنات و (90) مدرسة مختلطة، وذلك للعام الدراسي ولماسي

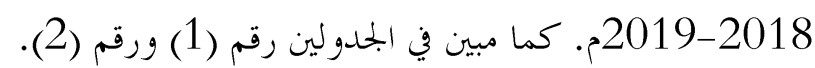


جدول رقم (1) يوضح المدارس الثانوية بحتمع البحث بمحافظة الأنبار

\begin{tabular}{|c|c|c|c|}
\hline عدد المدارس المختلطة & عدد مدارس البنات & عدد مدارس البنين & عدد المدارس الثانوية \\
\hline 90 & 216 & 281 & 1017 \\
\hline$\% 8.8$ & $\% 21.2$ & $\% 27.6$ & النسبة \\
\hline
\end{tabular}

جدول رقم (3) يو ضح معلمي مادة الكيمياء.مدارس المرحلة الثانوية

\begin{tabular}{|c|c|c|}
\hline المعلمات & المعلمين & عدد معلمي مادة الكيمياء \\
\hline 431 & 345 & 776 \\
\hline$\% 55.5$ & $\% 44.5$ & النسبة \% \\
\hline
\end{tabular}

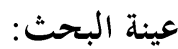

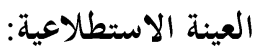

قام الباحث بتوزيع عينة استطلاعية بلغ حجمها (30) طالب وطالبة من طلاب الصف الخامس العلمي، حيث كان الذكور منهم (16) والإناث (14) و(10) من معلمي مقرر الكيمياء. العينة الأساسية:

تتكون العينة الأساسية من معلمي مادة الكيمياء وطلاب وطالبات الصف الخامس العلمي بالمرحلة الثانوية بكحافظة الأنبار تفصيلها كما يأتي في الجحول رقم (3) و الجلدول رقم (4).

جدول رقم (3) يوضح مدارس المرحلة الثانوية عينة البحث

\begin{tabular}{|r|r|r|}
\hline بنين| & بنات & 83 \\
\hline 34 & 96 & بنات \\
\hline
\end{tabular}

يتضح من الجحدول (3) ان عدد مدارس البنين بعينة البحث بلغ (83) مدرسة و مدارس البنات (96) مدرسة، بينما بلغ عدد المدارس المختلطة (34) مدرسة.

جدول رقم (4) يوضح المعلمين و الطلاب عينة البحث

\begin{tabular}{|c|c|c|c|}
\hline \multicolumn{2}{|c|}{ طلاب الصف الخامس العلمي } & \multicolumn{2}{|c|}{ معلمي مادة الكيمياء } \\
\hline طالبات & طلاب & المعلمات & المعلمين \\
\hline$\% 8.8$ & $\% 21.2$ & $\% 27.6$ & النسبة \\
\hline \multicolumn{2}{|c|}{310} & \multicolumn{2}{|c|}{297} \\
\hline
\end{tabular}


تكونت عينة الدراسة من (297) معلم كيمياء منهم (144) معلم و(153) معلمة، و(310) من طلاب الصف الخامس علمي، منهم (135) طالباً و(175) طالبة. وهو ما وضحته نتائج الجحدول (4).

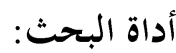

وقد اتبع الباحث عده خطوات في إعداد الاستبانة فيما يأتي وصفا لها. 1- بناء الاستبانة: رجع الباحث في إعداد هذه الاستبانة إلى المصادر الثابتة وتتمثل في: أ- الدراسات والبحوث السابقة التي تتناول استخدام الحاسوب في تدريس الكيمياء. ب- ما توصل إليه الباحث من خلال مقابلة عدد من معلمي مادة الكيمياء.

$$
\text { ت- فروض البحث. }
$$

2- اعداد الاستبانة في صورةا الأولية: من خحلال محاولة الربط بين ما جاء في هذه المصادر من جوانب

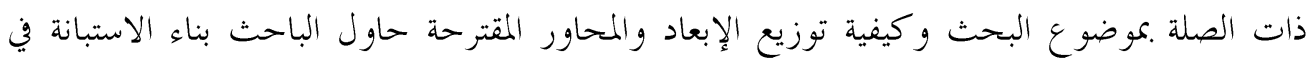

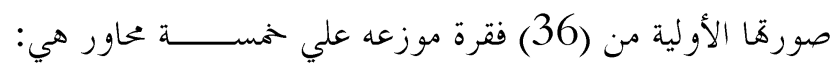

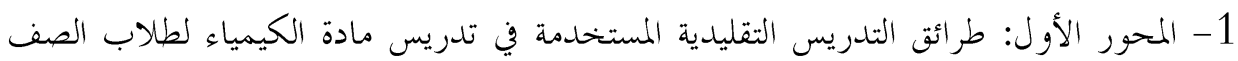
الخامس العلمي بالمرحلة الثانوية وعددها (7) فقرات.

2- المحور الثاني: أثر الحاسوب في تلدريس مادة الكيمياء للصف الخامس العلمي بالمرحلة الثانوية وعددها (7) فقرات.

3- المحور الثالث: العوامل التي تؤثر على التحصيل الدراسي في مادة الكيمياء وعددها (7) فقر ات. 4- المحور الرابع: استخدام الحاسوب في التدريس وعددها (8) فقرات. 5- المحور الخامس: معوقات استخدام الحاسوب في تدريس الكيمياء وعددها (7) فقرات. وقد استخدم الباحث في بناء الاستبانة الأولية مقياس خماسي في الإجابة علي الفقرات كما يلي (أوافق

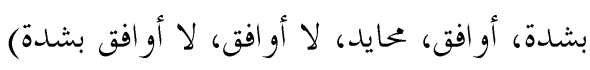

\section{تحكيم الاستبانة: - 20 - n}

بعد إعداد الاستبانة في صورها الأولية قام الباحث بعرضها على المشرف وقام بالتعديلات والتصويبات

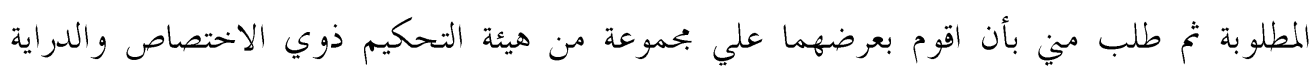

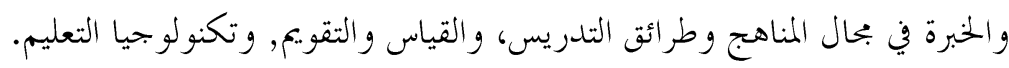




\section{أجر اء الاستبانة: (n \\ تكونت الاستبانة في صورةها النهائية من جز ائين هما:}

1- الجزء الأول: هو الخاص بجمع معلومات عامة عن المتغيرات الوصفية للمفحوصين، بغرض المقارنة

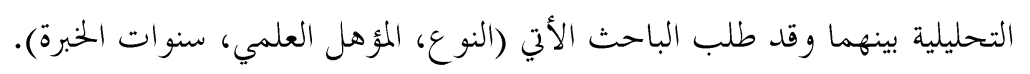

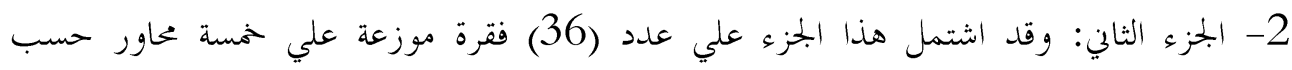

التسلسل الآتي:

1- المحور الأول: طرائق التدريس التقليدية المستخدمة في تدريس مادة الكيمياء لطلاب الصف الخامس العلمي بالمرحلة الثانوية وعددها (7) فقرات.

2- المحور الثاني: أثر الحاسوب في تدريس مادة الكيمياء الصف الخامس العلمي بالمرحلة

$$
\text { الثانوية وعددها (7) فقرات. }
$$

3- المحور الثالث: العوامل التي تؤثر على التحصيل الدراسي في مادة الكيمياء وعددها (7)

$$
\text { فقرات. }
$$

4- المحور الرابع: استخدام الحاسوب في التدريس وعددها (8) فقرات.

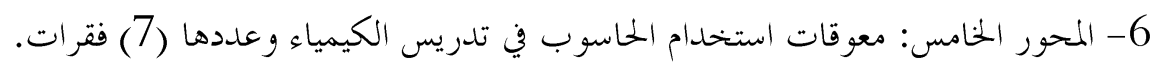

\section{صدق وثبات والاستبانة: - مدات}

بلغت قيمة معامل الثبات الكلي حوالى 0.89 وهى نسبة عإلىهة وهذا ثبات الاختبار وصلاحيته $0.94=0.89$

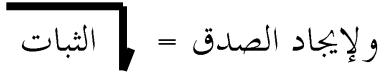

معامل الصدق يساوي (0.94) وهذا يدل على أن الاستبانة تتصف بالثبات والصدق الكبيرين جداً بما يمقق أغراض البحث، ويجعل التحليل الإحصائي سليماً ومقبولاً.

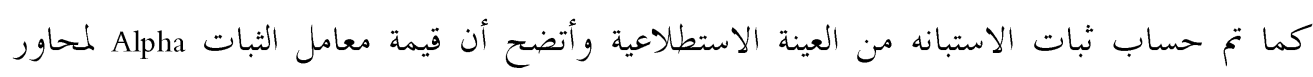
الاستبانة موضحة في الجحدول رقم (5). 
جدول رقم (5) يوضح معامل الصدق والثبات الذاتي للاستبانة

\begin{tabular}{|c|c|c|c|}
\hline الصدق & معامل الثبات & عدد العبارات & المحاور \\
\hline 0.87 & 0.75 & 7 & المحور الأول \\
\hline 0.81 & 0.65 & 7 & المحور الثاني \\
\hline 0.84 & 0.71 & 7 & المحور الثالث \\
\hline 0.91 & 0.82 & 8 & المحور الرابع \\
\hline 0.94 & 0.89 & 7 & المحور الخامس \\
\hline
\end{tabular}

تحليل بيانات استبانة معلمي مادة الكيمياء:

الشكل رقم (1) مدرسي مادة الكيمياء عينة البحث وفق متغير الجنس

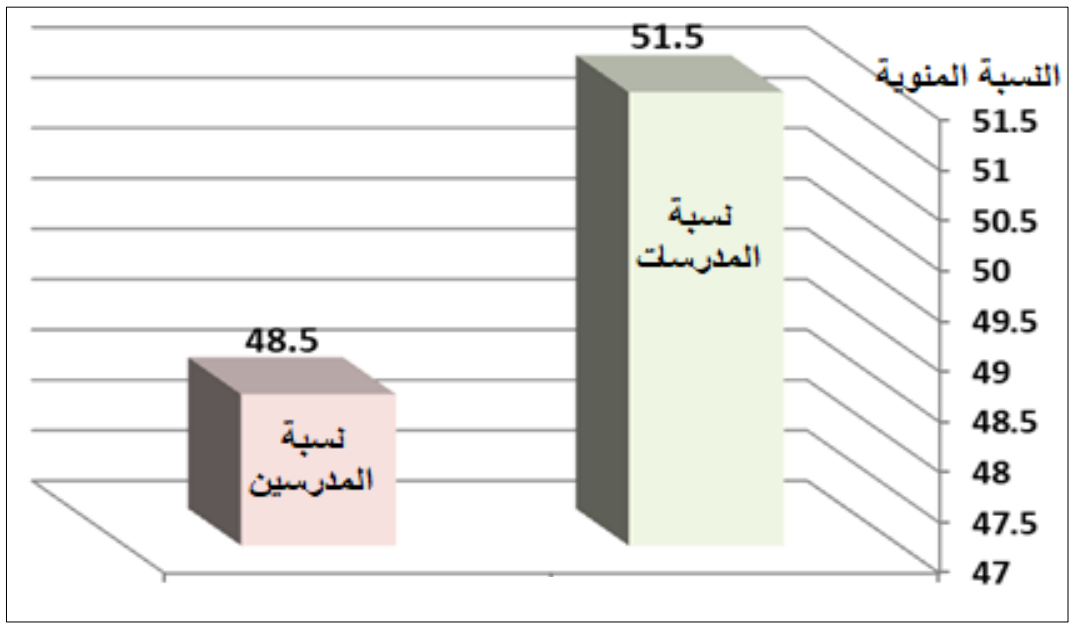

من الجمدول رقم (5) والشكل رقم (1) يتضح أن غالبية أفراد العينة من الإناث حيث بلغت نسبتهم 51.5\%، بينما بلغت نسبة الذكور 48.5\%، وذلك لإقبال الإناث على مهنة التدريس وقلة الفرص في المهن الأخرى 


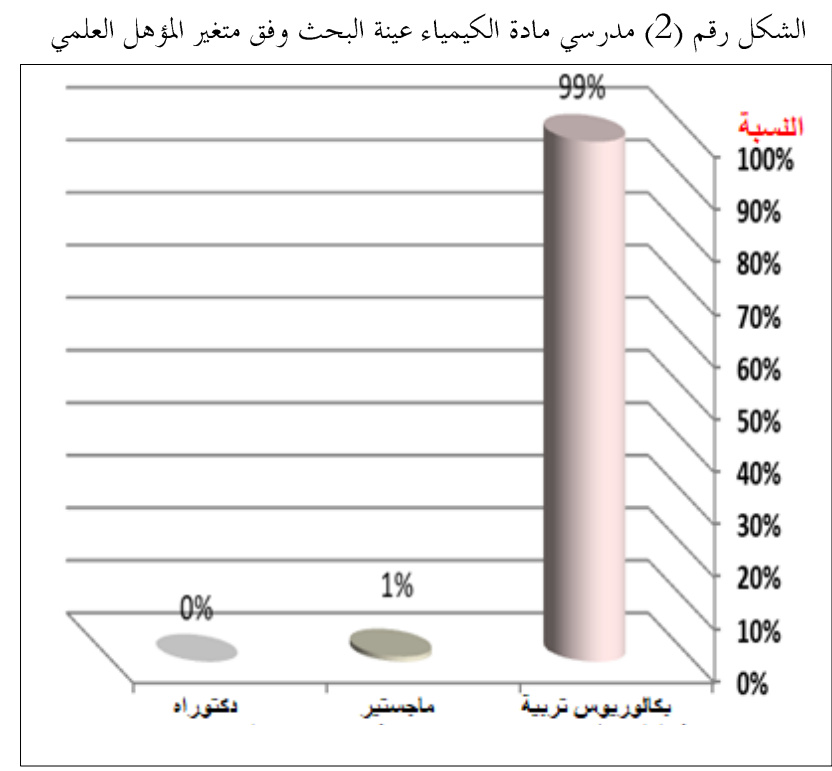

من الشكل رقم (2) يوضح ان أن 99\% من أفراد العينة مؤهلهم العلمي بكالريوس تربية، مما يشير إلى

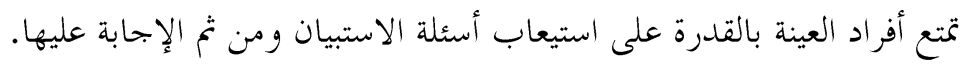

الشكل رقم (3) مدرسي مادة الكيمياء عينة البحث وفق متغير الخدمة

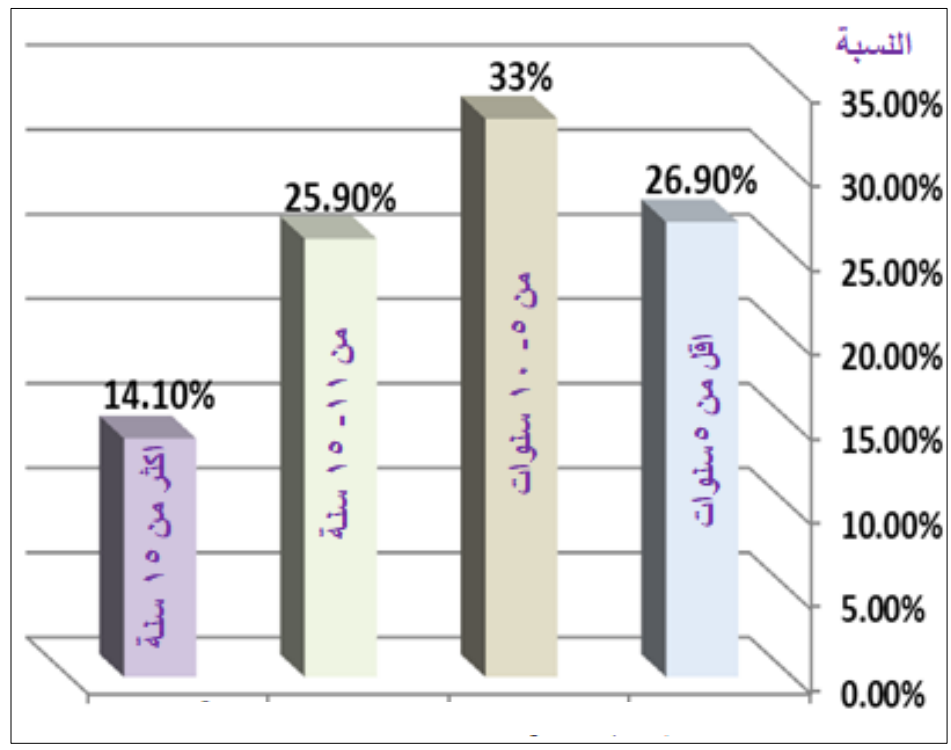




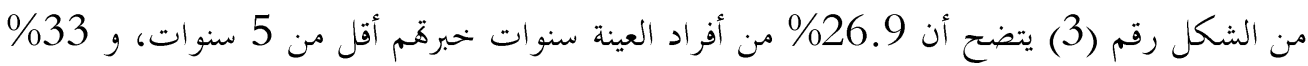

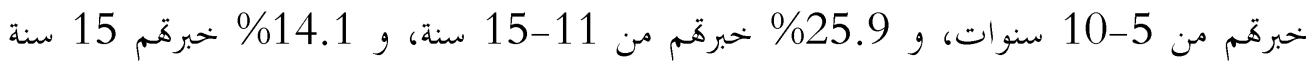
فأكثر ويرى الباحث ان هناك تدني في نسبة المعلمين الذين خبراقم اكثر من (15) سنة.

تحليل متغيرات استبانة الطلاب: - مان

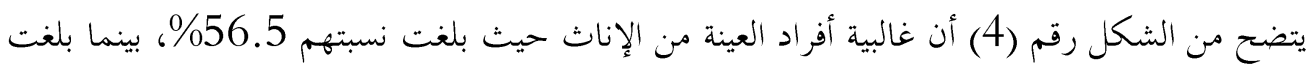
نسبة الذكور 43.5\%، وقد يعود السبب في ذلك لرغبة الإناث في التدريس أكثر من الذكور.

الشكل رقم (4) عينة طلبة البحث وفت متغير الجنس

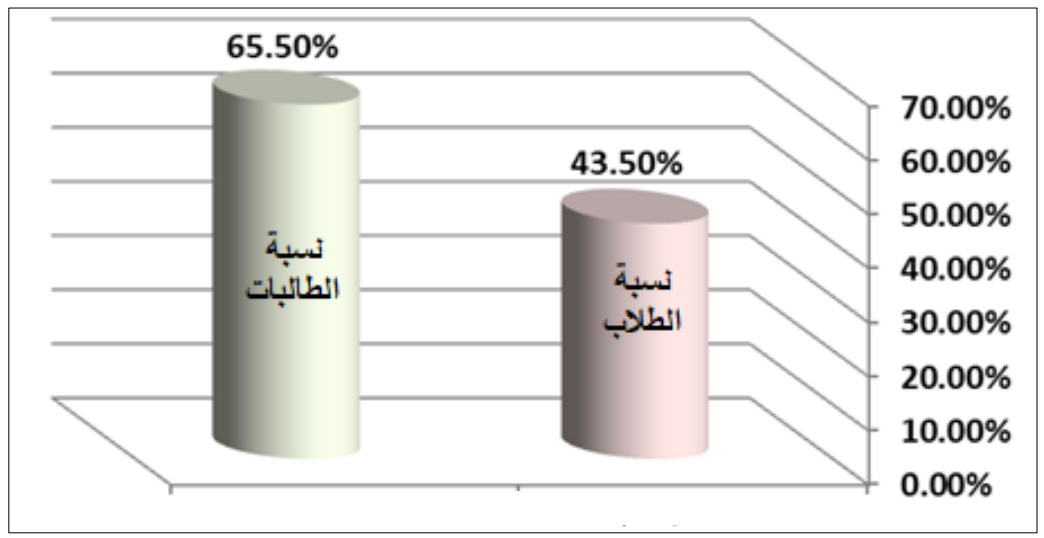

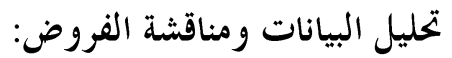
أولاً: تحليل ومناقشة فروض البحات وماقتة البروض: من خلال استبانة المعلمين عند تصحيح وتفريغ استمارات الاجابة

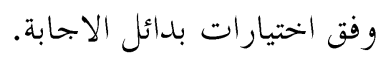

جدول رقم (6) الوسط المرجح والوزن المثوي لإجابات معلمي مادة الكيمياء حول عبارات محور (طرائق التدريس التقليدية

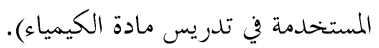

\begin{tabular}{|c|c|c|}
\hline الوزن المئوي & الوسط المرجح & العبارة \\
\hline 81.54882 & 4.077441 & 1. تتطلب توفر الخبرات الفنية المختصة بالمدرسة. \\
\hline 86.32997 & 4.316498 & 2. تثير الفوضى داخل الصف. \\
\hline 74.07407 & 3.703704 & 3. يسهل الحصول على الوسائل المستخدمة هيا. \\
\hline 75.21886 & 3.760943 & 4. سهلة الاستخدام لأفا ترتبط بالبيئة المحلية. \\
\hline 73.40067 & 3.670034 & 5. تراعي الفروق الفردية بين الطلاب. \\
\hline
\end{tabular}




\begin{tabular}{|c|c|c|}
\hline 80.26936 & 4.013468 & 6. تتيح اكمال المقرر في الزمن المحدد. \\
\hline 86.06061 & 4.30303 & 7. سهولة استخدام السبورة بالنسبة للمعلم. \\
\hline 79.748 & 3.9874 & ككل \\
\hline
\end{tabular}

يتبين من الجحدول رقم (6) ان كل الفقرات متحققة اذا كان الوسط المرجح لكل الفقرات أعلى من الوسط الفرضي 3، أن اعلى فقرتين كانت لا تثير الفوضى داخل الصف، وسهولة استخدام السبورة بالنسبة للمعلم.

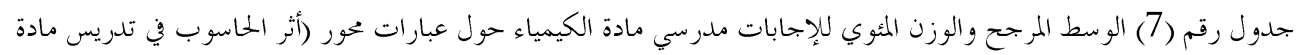

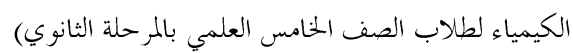

\begin{tabular}{|c|c|c|}
\hline الوزن المئوي & الوسط المرجح & 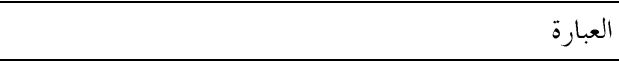 \\
\hline 89.22559 & 4.461279 & 1. طرق العرض بواسطة الحاسوب بتذب انتباه الطالب. \\
\hline 83.09764 & 4.154882 & 2. يخلو من التعقيد والغموض. \\
\hline 73.06397 & 3.653199 & 3. تثير التشويق لدى الطالب. \\
\hline 72.05387 & 3.602694 & 4. يوفر تدرييات للطلاب تساعد على فهم المقرر. \\
\hline 71.51515 & 3.575758 & 5. يوفر تطبيق عملي للمعلومات النظرية. \\
\hline 78.78788 & 3.939394 & 6. يزود المدرس .بعلومات عن طرق واستر اتيجيات التدريس. \\
\hline 75.75758 & 3.787879 & 7. يساعد المعلم على الأداء بشكل جيد. \\
\hline 77.6431 & 3.88216 & بمموع المحور ككل \\
\hline
\end{tabular}

جدول رقم (8) الوسط المرجح والوزن المئوي لإجابات مدرسي مادة الكيمياء حول عبارات محور (العوامل التي تؤثر على التحصيل

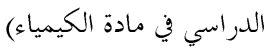

\begin{tabular}{|c|c|c|}
\hline الوزن المئوي & | الوسط المرجح & 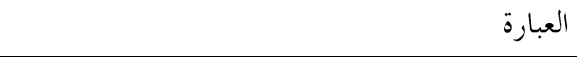 \\
\hline 80.60606 & 4.030303 & 1. كثرة أعداد الطلاب داخل الصف. \\
\hline 75.75758 & 3.787879 & 2. طول فترة المقررات الدراسية. \\
\hline 80 & 4 & 3. تركز المقررات على المعرفة أكثر من المهارة. \\
\hline 82.42424 & 4.121212 & 4. صعوبة المادة الدراسية المقررة. \\
\hline 66.66667 & 3.333333 & 5. استخدم المدرسين اسلوب التخويف والترهيب. \\
\hline 75.75758 & 3.787879 & 6. العيوب المتعلقة بطرق التدريس. \\
\hline 81.81818 & 4.090909 & 7. ضعف أداء المعلم. \\
\hline 77.4891 & 3.874459 & بمموع المحور ككل \\
\hline
\end{tabular}


جدول رقم (9) : يوضح التكرارات والنسب المئوية لإجابات معلمي مادة الكيمياء حول عبارات محور (استخدام الحاسوب في التدريس)

\begin{tabular}{|c|c|c|}
\hline 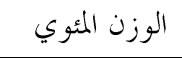 & الوسط المرجح & 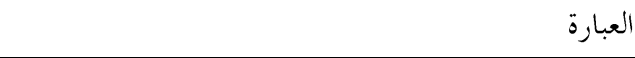 \\
\hline 79.39394 & 3.969697 & 1. يساعد الطالب على فهم المادة بسرعة. \\
\hline 81.21212 & 4.060606 & 2. ينمي روح الإبداع والاستكشاف لدى الطالب. \\
\hline 78.78788 & 3.939394 & 3. يثير الحوار بين الطلاب داخل الفصل. \\
\hline 69.69697 & 3.484848 & 4. يعطي فرصة للتواصل بين المعلم والطلاب. \\
\hline 84.84848 & 4.242424 & 5. ينمي مهار ات الطالب في استخدام الأجهزة والأدوات. \\
\hline 83.0303 & 4.151515 & 6. - 5 - 5لل من الملل. \\
\hline 72.12121 & 3.606061 & 7. يجعل الطالب قادراً على مواكبة التطورات التقنية. \\
\hline 81.81818 & 4.090909 & 8. يساعد المعلم على تطوير أساليب عرض المادة العلمية. \\
\hline 78.86368 & 3.94318 & بحموع المحور ككل \\
\hline
\end{tabular}

جدول رقم (10) يوضح التكرارات والنسب المئوية للإجابات معلمي مادة الكيمياء حول عبارات محور (معوقات استخدام الحاسوب في تدريس الكيمياء)

\begin{tabular}{|c|c|c|}
\hline 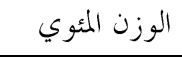 & الوسط المرجح & 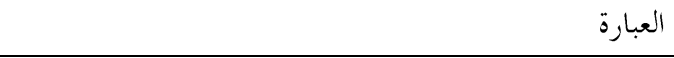 \\
\hline 75.15152 & 3.757576 & 1. عدم توفر الميزانية المالية المخصصة لدعم معامل الحاسوب. \\
\hline 76.36364 & 3.818182 & 2. عدم توفر المواد والأدوات المعملية. \\
\hline 87.07071 & 4.353535 & 3. عدم توفر الكهرباء بصورة مستمرة. \\
\hline 70.30303 & 3.515152 & 4. عدم توفر البربحيات التعليمية المخصصة لتدريس المادة. \\
\hline 78.78788 & 3.939394 & 5. نقص الخبرات الفنية المتخصصة بالمدرسة. \\
\hline 83.0303 & 4.151515 & 6. البيئة المدرسية لا تدعم التدريس بالحاسوب. \\
\hline 27.96633 & 1.398316 & \\
\hline 79.39394 & 3.969697 & 7. لا يتناسب المقرر مع عدد الخصص المقررة. \\
\hline 78.5858 & 3.92929 & ع ع المحور ككل \\
\hline
\end{tabular}

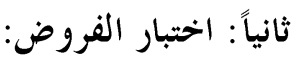
نص العبارة للفرض الأول: يستخدم معلمو مادة الكيمياء طرائق التدريس التقليدية في تدريس طلاب الصف الخامس العلمي بالمرحلة الثانوية. 
جدول رقم (11) يوضح الوصف الإحصائي وقيم اختبار مربع كاي لعبارات محور (طرائق التدريس التقليدية المستخدمة في تدريس مادة الكيمياء ) الخاص باستمارة معلمي مادة الكيمياء.

\begin{tabular}{|c|c|c|c|c|c|}
\hline الدلالة & الاحتمالية & قاي & الالمخر افياري & الوسط الحسابي & العبارة \\
\hline دالة & 0.00 & $142.18 \mathrm{a}$ & .8195 & 4.145 & 1 1. لامدر تتطلب توفر الخبرات الفنية المختصة \\
\hline دالة & 0.00 & $215.04 a$ & .6479 & 4.3165 & 2. لا تثير الفوضى داخل الصف \\
\hline دالة & 0.00 & $213.89 b$ & .9655 & 3.704 & 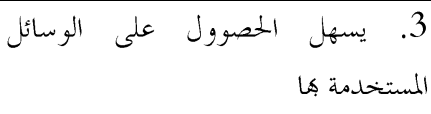 \\
\hline دالة & 0.00 & $112.92 b$ & 1.033 & 3.761 & 4. المحلية سهلة الاستخدام لأها ترتبط بالبيئة \\
\hline دالة & 0.00 & $149.05 b$ & 1.176 & 3.451 & 5. تراعي الفروق الفردية بين الطلاب \\
\hline 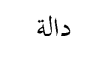 & 0.00 & $212.48 b$ & .9514 & 4.013 & 6. تتيح اكمال المقرر في الزمن المحدد \\
\hline دالة & 0.00 & $222.02 a$ & .7041 & 4.303 & 7لمعلم سولة استخدام السبورة بالنسبة \\
\hline
\end{tabular}

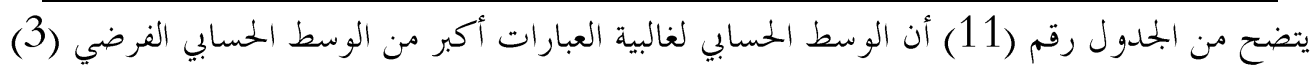

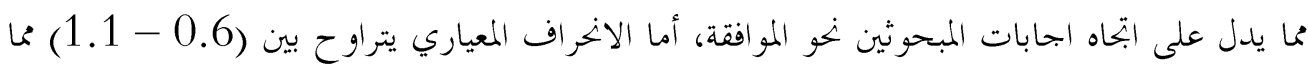

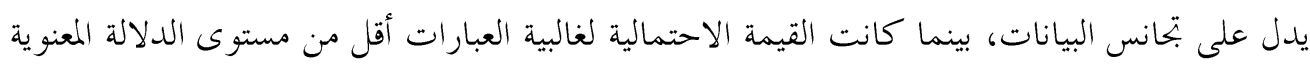

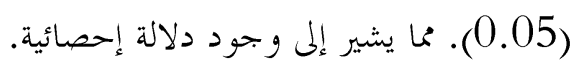

الحخائة:

يشتمل هذا الفصل عن اهم النتائج التي توصل اليها البحث والتوصيات والمقترحات .

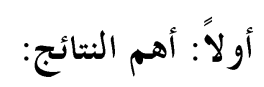

1. يستخدم معلمو مادة الكيمياء طرائق التدريس التقليدية في تدريس طلاب الصف الخامس العلمي بالمرحلة الثانوية.

2. للحاسوب أثر مهم في تدريس مادة الكيمياء لطلاب الصف الخامس العلمي بالمرحلة الثانوية. 3. توجد عدة عوامل تؤثر على التحصيل الدراسي في مادة الكيمياء لطلاب الصف الخامس العلمي بالمرحلة الثانوية. 4. لا تتوفر بالمدارس الثانوية ميزانية مالية مخصصة لدعم معامل الحاسوب. باسب. 
5. يسهم استخدام الحاسوب في التدريس في رفع التحصيل الدراسي لطلاب الصف الخامس العلمي في مادة الكيمياء بالمر حلة الثانوية. 6. قلة تناسب مقرر الكيمياء مع المدة الزمنية للمقرر. 7. قلة توفر البربحيات التعليمية والخبرات الفنية شكل عائقاً من عو ائق التعليم باستخدام الحاسوب.

بناءاً على النتائج تقدم البحث بالتوصيات الآتية: 1. ضرورة هيئة البيئة المدرسية لاستخدام الحاسوب في بي التدريس. 2. ت تخصيص جزء من ميزانية المدارس لشراء أجهزة الحاسوب اللازمة.

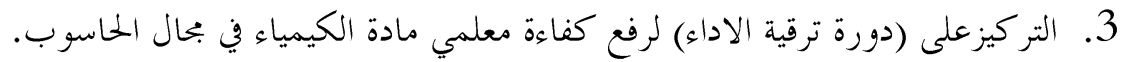

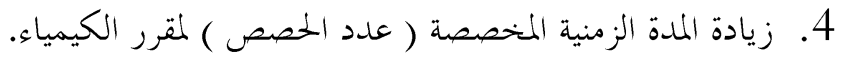

\section{ثالثاً: : المقتر حات:}

لاستكمال مانقص في هذا البحث يقترح الباحث الموضوعات الآتية:

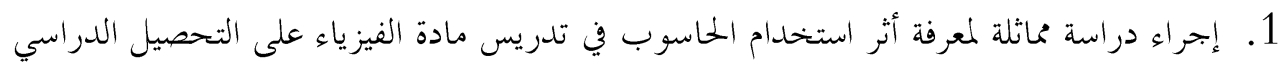

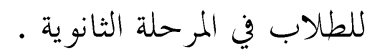
2. وضع تصور لتدريب معلمي مادة الكيمياء علي كيفية استخدام الحاسوب ومستحدثاته في

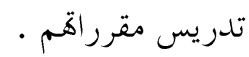
3. استخدام المعامل الافتراضية في تدريس مادة الكيمياء لطلاب الصف الخامس العلمي.

1. إبراهيم صادق الخطيب و مصطفى تركي عبيد، (2011)، الكيمياء العامة، دار المسيرة للطباعة والنشروالتوزيع، ط4، عمان، الأردن. 2.

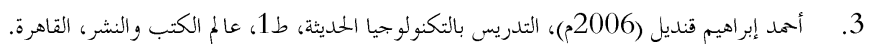

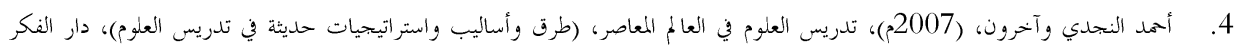
العربي، القاهرة.

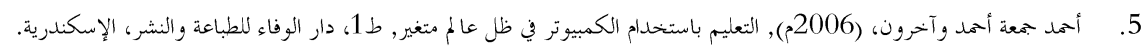
6. 7. 8.

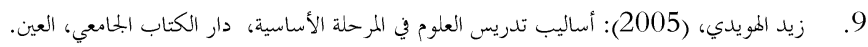

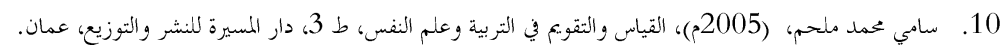


11. سهيلة خحسن كاظم الفتلاوي، و أمد هلالي، (2006 )، المنهاج التعليمي والتوجه الإيديولدي (النظرية والتطبيق )، دار الشروق،ط1،عمان،

$$
\text { الأردن. }
$$

12. شاهد ربكي عليان، (2010م)، مناهج العلوم الطبيعية وطرق تدريسها النظرية والتطبيقية، دار المسيرة للنشر والتوزيع، عمان.

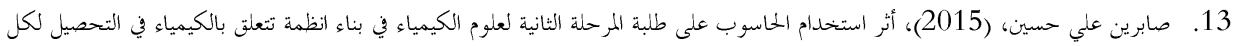

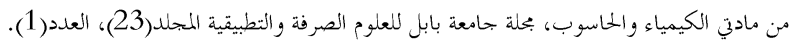

14. صالح محمد علي أبوجادو، (1998)، علم النفس التربوي، دار المسبرة للنشر والتوزيع والطباعة، عمان، الأردن.

15. صبحي أبو جالة، (2007)، تدريس بتحارب العلوم في ضوء استراتيجيات التدريس المعاصرة، مكتبة الفلاح للنشر والتوزيع، الكويت.

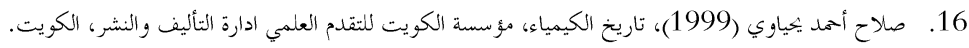

$$
\text { 17. . صلاح الدين العمرية، (2005)، طرق تدريس العلوم، مكتبة المجمع العربي للنشر، عمان. }
$$

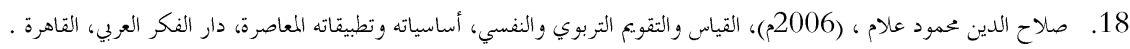

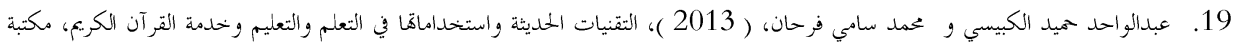

$$
\text { المجتمع العربي، عمان، الاردن. }
$$

